\title{
Natural Resources Perspective of the Balanced Scorecard: Balance and Boundaries
}

\section{By Sean P. Kelly and Rob Ravenscroft}

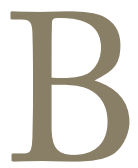

alance is defined as "a harmonious proportion of elements in a design." 1 (p. 45) Finding balance is difficult in any business. Finding balance within a ranch business can be extremely challenging. Several aspects of ranch must be brought into harmony to create a sustainable business. Some ranches might focus solely on cattle production and lose sight of the range and natural resources. The result can be poor range production following a drought. Some ranches might focus solely on the natural resources and cattle production and lose sight of the quality of life they are trying to achieve. The result might be that sons or daughters choose not to return to the ranch. Balancing livestock, rangeland resources, finances, and quality of life for a ranch that has a vision of sustainability and profitability is extremely important.

The Balanced Scorecard looks at a ranch from different perspectives with strategies and metrics for each perspective. Some examples of perspectives include: production, natural resources, financial, customers, and quality of life. The natural resources perspective is the foundation for all other perspectives of a ranch. The natural resources to a large extent also set the boundaries for each of the other perspectives on a ranch. These can include the soil, rangeland, wildlife, water, forage crops, and aesthetics. They also determine the number of cattle that can be stocked or the number of wildlife that can be sustained, as well as the amount of forage crops or hay that can be produced.

By determining the boundaries for the natural resources perspective, a ranch manager can unlock the potential and un-

This article has been peer reviewed. foreseen opportunities within other perspectives of the ranch business. For example, if a ranch manager determines that the ranch can support more livestock or wildlife due to increased rangeland production from proper stocking rates, this can generate more income and provide the opportunity for a son or daughter to return to the ranch. Or if a ranch manager determines there is potential for additional income from recreational activities, this decision can provide the opportunity for increased financial security and lower stress levels within the family. In any case, determining the bound-aries for the natural resources defines the limits of the ranch. However, the limits might be far beyond what was originally perceived, or they might be a fraction of what is currently being harvested.

This brings us back to the simple definition of balance: a harmonious proportion of elements in a design. For this discussion, think of the Balanced Scorecard as the "design" or plan for ranch management. The perspectives are the "elements" or essential components of the ranch business. Finding a harmonious proportion of each perspective is the challenge for every rancher today and for the future.

\section{Strategies and Metrics}

When determining strategies, a ranch manager usually is identifying and addressing needs for change. However, there are often features of the resource that should stay as they are. Whether for change or to encourage stability, strategies need to address the gaps between the present reality and the desired future defined in the vision. The following are some questions ranch managers might ask in order to develop strategies:

1) What can we control?

2) What do we want to keep? 
3) What don't we want to keep?

4) What do we need to change, or reach for?

5) What actions should we take?

These five questions can provide a powerful form of intervention for a ranch business. Asking and answering them causes management to think about their ranch at its very core. By going deeper and affecting the thinking and decision making of a ranch we are affecting the very structure of the ranch business. This can lead to the development of strategies with high leverage points that are long-lasting and self-sustaining for the ranch. ${ }^{2}$

When strategies are chosen, the next questions are:

1) What will indicate success?

2) What measuring tools can we use?

Each strategy will have metrics that can measure the success toward fulfilling each strategy and toward achieving the vision of the ranch. The metrics or indicators must be quantifiable, relevant to the operation, and easy to document. The metrics might be somewhat subjective; however, they should be both leading and lagging. Leading metrics are proactive and can trigger points for management action. Lagging metrics are historical and measure progress toward the strategies. ${ }^{3}$ The following are some examples of strategies and metrics (Table 1), but are not intended to be recommendations, because every ranching business will have its own unique strategies and metrics.

\section{Strategy 1: Flexible Stocking Rate That Equals Carrying Capacity Based on Current Growing Conditions}

Determining proper stocking rates and carrying capacity is the foundation for proper rangeland management. Stocking rates are a key leverage point that is entirely under a ranch manager's control. Regardless of the geographical location of the ranch, stocking rates that match the current carrying capacity of the rangeland should be a cornerstone for proper rangeland management. It's important to remember that carrying capacity is a variable figure and changes with growing conditions. A ranch manager should be aware of the carrying capacity of the ranch in both high and low precipitation years.

In order for the ranch manager to adjust stocking rates to match the carrying capacity, the manager has to be flexible with the stocking rates. Flexible stocking rates allow for rapid destocking in the event of a drought and rapid increase in stocking rates in wet years. Possibly changing to a $70 \%$ core cow herd and 30\% stocker operation will allow more flexible stocking rates. Also by having a mixture of classes of livestock, a ranch manager will have more marketing opportunities if stocking rates need to be adjusted. Networking and developing relationships with livestock order buyers or feedlots are other tools that can be utilized by ranch managers. Many livestock order buyers already have the vast network of connections with salebarns, feedlots, and other ranches if cattle need to be bought, sold, or moved quickly. They can also provide marketing advice in the event that cattle need
Table 1. Example strategies and corresponding metrics for the natural resources perspective of the Balanced Scorecard for a ranch

1. Flexible stocking rate that equals carrying capacity based on current growing conditions

- Maximum forage utilization $=60 \%$ except for "treatment" areas

- Cow BCS $=5$ at weaning

- Financial metrics $=$ positive

- Transects trend = positive

2. Drought management plan integrated into the overall ranch operation plan

- Implement when necessary

- Maximum forage utilization $=50 \%$

- Cow BCS $=5$ at weaning

- Transects trend = positive

- Was the drought plan successful?

3. Wildlife needs are part of grazing and investment plans

- Grazing, fire, chemical, and mechanical treatments applied as planned

- Prime grouse nesting areas ungrazed in May

- Bird and deer counts = goals

- Photo points and transects = trending toward goals

4. Maximize ability of watersheds to hold water

- Grazing is planned, executed, and adjusted to allow plants to recover from grazing

- Maximum forage utilization $=60 \%$

- Photo points show increasing riparian vegetation

- Photo points and transects show decreasing bare ground

5. Apply grazing, fire, chemical, or mechanical treatments to control brush or invasive species

- 3\% brush cover for targeted area

- Photo points show desired trend

- Maximum forage utilization $=60 \%$

- Increased stocking rates over time

- Bird and deer counts = goals

to be sold or bought quickly so the financial metrics of the ranch remain positive.

Monitoring the maximum forage utilization is a leading metric because it determines what stocking rates should be applied and will determine when stocking rates need to be adjusted. Forage utilization can be determined by ocular estimates, forage mapping, or by setting up exclosure cages. Ocular estimates should be used only if the manager has the required experience and knowledge of proper rangeland management. If a manager is not comfortable using ocular estimates, exclosure cages are a useful tool. A recording of 
the current stocking rate along with evaluating the health of the plant community inside and outside of the exclosure cage can help a manager determine the percent use of the rangeland. ${ }^{4}$ From these measurements a manager can then determine what adjustments need to be made to the stocking rates. Cow body condition score (BCS) is a lagging indicator because it will determine if the proper amount of nutritional forage was provided to the cow herd. If a manager does not provide an adequate amount of nutritional forage the BCS of the herd may fall to levels that will in turn hurt reproductive performance of the cowherd. ${ }^{5} \mathrm{~A}$ ranch manager must keep in mind that in some cases cow BCS can lag too far behind the condition of the rangeland. Overuse of the rangeland resource can happen before the nutritional requirements negatively affect a cow's BCS. Financial metrics are lagging indicators because they determine if the ranch made or lost money when stocking rates were adjusted by selling or buying cattle. In order for a ranch to be sustainable for the long term, financial metrics need to be positive. Rangeland transects determine the health and condition of the rangeland. Transects are lagging indicators because they indicate if the rangeland health is being negatively or positively impacted by the applied stocking rates.

The importance of including both leading and lagging indicators is clearly shown with Strategy 1 . The leading indicator tells us what stocking rates to use for the ranch. The lagging indicators indicate if the stocking rates were successful in maintaining or improving rangeland health, maintaining or improving cow BCS, and probably most importantly if we were profitable with the applied stocking rates, which leads to long-term sustainability.

\section{Strategy 2: Drought Management Plan Inte- grated Into the Overall Ranch Operation Plan}

On a majority of ranches across the United States, drought plays a major factor in ranch management. A ranch manager must understand that drought is cyclical and it's not a matter of if it's going to happen, but when it will happen. Having a successful drought management plan integrated into the overall management plan of the ranch, and more importantly, implementing it when necessary, will go a long way toward the sustainability and longevity of a ranch.

In order for a drought management plan to be successful it must have measures and triggers in place. Examples can include: identifying critical evaluation dates for amount of forage produced and moisture received, determining amount of soil moisture on key range sites at the beginning of the growing season, and specific stocking rate adjustments in terms of how many and how long. ${ }^{6} \mathrm{~A}$ ranch manager should be familiar with historical rainfall data on the ranch which will also aid in predicting an oncoming drought as well as how long the drought might last.

The first leading metric is to implement the plan when necessary. There are several reasons why a ranch manger may be reluctant to implement the drought plan. Financial con-

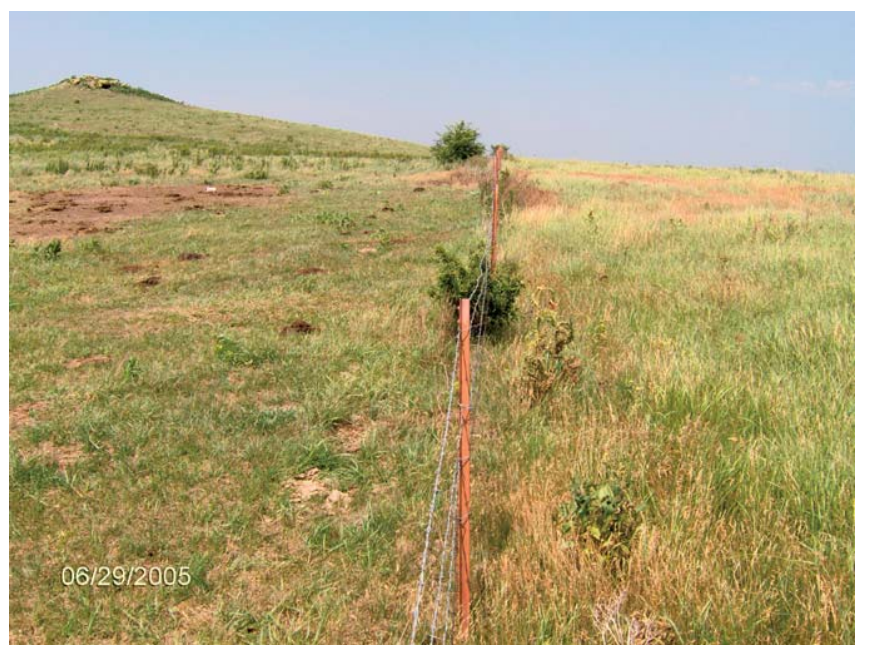

A fenceline contrast showing overgrazed rangeland and more healthy rangeland in Riley County, Kansas.

siderations, mental models, government policy, or the scale of the drought are a few examples. ${ }^{7}$ In order to minimize the hardships that may be encountered by the resources, finances, and the family during a drought, it's extremely important for the ranch manager to follow the plan, stay flexible, and don't second guess decisions.

The third leading metric is making sure the maximum forage utilization rate does not exceed $50 \%$. This metric is the same as the one listed in Strategy 1. Both leading and lagging metrics can overlap between strategies. Monitoring the maximum forage utilization gives us the proper stocking rates within the drought plan. Cow BCS of 5 at weaning and positive transect trends are both lagging indicators. They indicate if the drought management plan was successful in maintaining range condition and proper herd condition at weaning. The final metric could be determining if the overall drought plan was successful for the ranch. Adjustments can then be made to the drought plan if necessary.

\section{Strategy 3: Wildlife Needs Are Part of Grazing and Investment Plans}

Wildlife management is becoming a crucial component for ranch management of the 21st century. Whether it's for income from hunting or purely for aesthetic value, the needs of wildlife must be included in the overall grazing and investment plans. For the majority of ranches across the country, proper rangeland health and condition for wildlife will go hand in hand with proper grazing plans. ${ }^{8} \mathrm{~A}$ ranch manager must not forget the value that a healthy and sustainable wildlife population has on the general population not connected to ranching. Positive word-of-mouth from urban hunters or wildlife observers can go a long way toward improving the perception of grazing livestock and ranching in general.

The application of grazing, fire, chemical, and mechanical treatments as planned is a leading metric. One example might involve the removal of a percentage of cedar trees by either chemical or mechanical means to improve habitat for 


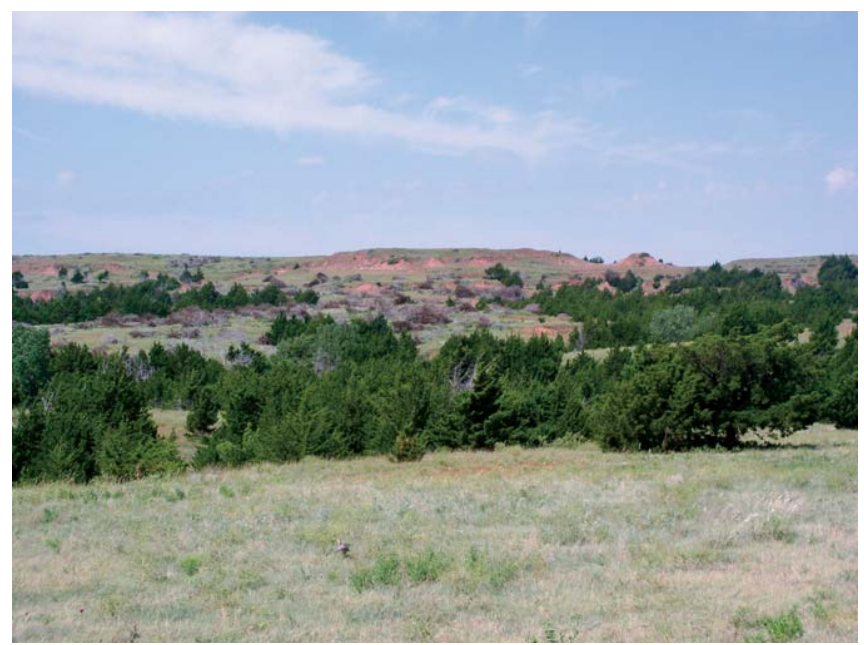

Mechanical treatment of cedar tree invasion in Comanche County, Kansas. A prescribed burn then follows the mechanical treatment to help prevent new seedlings from returning.

grassland bird species. Avoiding nesting areas for certain bird species at a particular time is also a leading metric. Being proactive with our grazing plans ensures proper nesting times for certain bird species. Assessing if bird and deer counts meet desired goals are both leading and lagging metrics. The counts set a goal for the amount of wildlife desired. The counts also determine if the grazing plans and various habitat treatments were successful in maintaining or increasing the amount of wildlife. Using photo points or transects are also lagging indicators that help us determine if the various wildlife management practices are maintaining or improving rangeland health.

\section{Strategy 4: Maximize Ability of Watersheds to Hold Water}

The cattle, wildlife, and the rangeland all need water for survival and sustainability. Maintaining a healthy and functioning water cycle on the ranch helps optimize the ability of watersheds to hold water on a ranch and go a long way toward sustaining healthy cattle, wildlife, and rangeland. If the water for livestock and wildlife is pumped from the ground, healthy watersheds that can hold water and allow precipitation to penetrate into the ground will help sustain or improve the water tables on the ranch as well. ${ }^{9}$

Developing grazing plans that provide adequate rest for the rangeland and provide adequate residual cover for maximizing the ability of watersheds to hold water is a leading metric. Proper stocking rates determined from the maximum grazing utilization is also a leading indicator. Proper stocking rates prevent overgrazing of the rangeland. Increased runoff and bare ground can result from overgrazing, which decreases the ability of watersheds to hold water on the ranch. ${ }^{9}$ Photo points of riparian areas or gullies are very effective lagging indicators that tell us if the grazing plans and stocking rates are improving or maintaining the ability of the watersheds to hold water.

\section{Resources for Rangeland Monitoring}

\section{Natural Resources Conservation Service \\ www.nrcs.usda.gov}

\section{Interpreting Indicators of Rangeland Health \\ www.blm.gov/nstc/library/techref.htm}

\section{Jornada Monitoring Manual}

http://usda-ars.nmsu.edu

The Grazing Manager Software

www.agren-inc.com/tgm/

\section{Strategy 5: Apply Grazing, Fire, Chemical, or Mechanical Treatments to Control Brush or Invasive Species}

Brush and invasive species can be a limiting factor in achieving desired rangeland production by competing with desirable forage species for moisture, light, and soil nutrients. A ranch manager must consider the economic benefits and limitations when developing a strategy for control of brush and invasive species. Balancing the expected value of implementing the treatments with the cost of implementing the treatments is essential for long-term sustainability. ${ }^{10}$

\section{Summary}

Range condition, wildlife counts, photo points, and grazing utilization are all metrics that can be used for each strategy if desired. They provide a good mixture of both leading and lagging indicators, which is essential for a successful Balanced Scorecard. ${ }^{3}$ However, a baseline of information or inventory is required before any monitoring can take place. The baseline measurements help a ranch manager determine the initial stocking rates and carrying capacity of the ranch. These measurements can be taken by a rancher or employees, or you may consider contracting with a range professional. Many natural resources services are provided by the USDA-Natural Resources Conservation Service.

When developing a monitoring program, make measurements as easy as possible and multipurpose. Set up transects or exclosure cages in areas where both range and wildlife improvements are objectives. The use of photo points is also a powerful monitoring tool for measuring long-term success toward the desired strategies. The use of computer software programs in conjunction with field measurements is an excellent tool for monitoring. "The Grazing Manager" software (TGM) developed by Dr Mort Kothmann of Texas A\&M University is a public domain software free to the public. It can be used to assist the ranch manager in monitoring and decision making regarding range improvement, livestock performance, management triggers, grazing and livestock records, and growing conditions. The Jornada Monitoring Manual developed by the USDA, Agricultural Research Service, Jornada Experimental Range is also an excellent 
tool that can be utilized by a ranch manager in developing a monitoring program.

The most important consideration in successfully meeting natural resource management goals is the ability to be flexible and adapt to resource conditions. Rangeland health and drought plans are priorities; a ranch manager must try and make other perspectives adapt if the ranch's vision includes long-term sustainability and profitability.

Authors are Graduate Fellow, King Ranch Institute for Ranch Management, Texas AEऽM University-Kingsville, Kingsville, TX 78363-8202 (Kelly); and Rancher and Rangeland Consultant, Lincoln, NE 68516, rravenscroft@neb.rr.com (Ravenscroft).

\section{References:}

1. Webster's New World Dictionary. 1995. New York, NY: Simon and Schuster. 694 p.

2. Goodman, M. 2002. Systems thinking: A language for learning and action. Hopkinton, MA: Innovation Associates Organizational Learning, Inc. 214 p.

3. Kaplan, R. S., and D. P. Norton. 1996. The balanced scorecard. Boston, MA: Harvard Business School Press. 323 p.
4. Natural Resources Conservation Service. 1997. National range and pasture handbook. Washington, DC: United States Department of Agriculture. 5. 520 p.

5. Pruitt, R. J., And P. A. Momont. 1988. Effects of body condition on reproductive performance of range beef cows. SD Beef Report. Brookings, SD: South Dakota State University. $80 \mathrm{p}$.

6. Reece, P. E, J. D. Alexander III, and J. R. Johnson. 1991. Drought management on range and pastureland: A handbook for Nebraska and South Dakota. EC 91-123. Lincoln, NE: University of Nebraska, Nebraska Cooperative Extension. 23 p. 7. Dunn, B. H., A. Smart, and R. Gates. 2005. Barriers to successful drought management: why do some ranchers fail to take action? Rangelands 27(2):13-16.

8. Sayre, N. F. 2001. The new ranch handbook: A guide to restoring western rangelands. Santa Fe, NM: The Quivira Coalition. 102 p.

9. Holechek, J. L., R. D. Pieper, and C. H. Herbel. 2001. Range management principles and practices. Upper Saddle River, NJ: Prentice Hall. 587 p.

10. Towne, G., and P. D. Ohlenbusch. 1992. Rangeland brush management. MF-1021. Manhattan, KS: Kansas State University, Cooperative Extension Service. 4 p. 